\title{
TU/e EmonOWEN

\section{Long-range electron interferences at a metal surface induced by buried nanocavities}

\section{Citation for published version (APA):}

Kurnosikov, O., Nietsch, J. H., Sicot, M. V., Swagten, H. J. M., \& Koopmans, B. (2009). Long-range electron interferences at a metal surface induced by buried nanocavities. Physical Review Letters, 102(6), 066101-1/4. [066101]. https://doi.org/10.1103/PhysRevLett.102.066101

DOI:

10.1103/PhysRevLett.102.066101

Document status and date:

Published: 01/01/2009

\section{Document Version:}

Publisher's PDF, also known as Version of Record (includes final page, issue and volume numbers)

\section{Please check the document version of this publication:}

- A submitted manuscript is the version of the article upon submission and before peer-review. There can be important differences between the submitted version and the official published version of record. People interested in the research are advised to contact the author for the final version of the publication, or visit the $\mathrm{DOI}$ to the publisher's website.

- The final author version and the galley proof are versions of the publication after peer review.

- The final published version features the final layout of the paper including the volume, issue and page numbers.

Link to publication

\section{General rights}

Copyright and moral rights for the publications made accessible in the public portal are retained by the authors and/or other copyright owners and it is a condition of accessing publications that users recognise and abide by the legal requirements associated with these rights.

- Users may download and print one copy of any publication from the public portal for the purpose of private study or research.

- You may not further distribute the material or use it for any profit-making activity or commercial gain

- You may freely distribute the URL identifying the publication in the public portal.

If the publication is distributed under the terms of Article 25fa of the Dutch Copyright Act, indicated by the "Taverne" license above, please follow below link for the End User Agreement:

www.tue.nl/taverne

Take down policy

If you believe that this document breaches copyright please contact us at:

openaccess@tue.nl

providing details and we will investigate your claim. 


\title{
Long-Range Electron Interferences at a Metal Surface Induced by Buried Nanocavities
}

\author{
O. Kurnosikov, J. H. Nietsch, M. Sicot, H. J. M. Swagten, and B. Koopmans \\ Department of Applied Physics, cNM, Eindhoven University of Technology, 5600MB Eindhoven, The Netherlands
}

(Received 26 September 2008; published 9 February 2009)

\begin{abstract}
Apparent $c(2 \times 2)$ superstructures within the narrow beams of an interference pattern spreading in the $\langle 100\rangle$ directions at the surface of $\mathrm{Cu}(001)$ are observed by scanning tunneling microscopy. These features are induced by electron scattering from Ar- and Ne-filled subsurface nanocavities. The beams originate from electron anisotropy resulting in focusing of bulk electrons. We developed a model providing a good agreement between simulations and experiments. Particularly, a simple explanation of the angular distribution for the interference pattern and the period in the superstructure is found.
\end{abstract}

PACS numbers: 68.37.Ef, 61.72.J-, 73.21.Fg

Electron interference at a surface is well-known phenomenon and can be induced by electron scattering at surface defects [1] or by subsurface scattering at interfaces [2]. Interestingly, nanosized reflectors can be formed by aggregated noble-gas nanocavities [3], which have been studied in different metals and semiconductors for their formation and growth [4], and for surface and bulk structural changes [5,6]. However, only recently Ar-filled nanocavities were studied with scanning tunneling microscopy (STM) aiming particularly at the quantum well (QW) states formed between surface and nanocavity [7,8]. It was demonstrated that the area of modified surface conductance of $\mathrm{Al}(111)$ generally corresponds to the shape of the upper facet of the subsurface object [8]. For Arnanocavities in $\mathrm{Cu}$, it was shown [9] that the spatial distribution of the conductance in the area right above the upper cavity facet is much more complicated and additionally determined by the band structure anisotropy of the host material and the related focusing of hot electrons [10]. In the paper of Kurnosikov et al. [9], also preliminary data were shown for conductance modifications away from the center of the nanocavity for specific crystallographic directions. Although this was tentatively ascribed to the influence of electron anisotropy, the authors have stressed the lack of a consistent description and analysis of the experimental STM image, which did not allow for a conclusive physical understanding at that time.

Inspired by these initial observations, in this Letter we entirely focus on long-range electron interferences due to subsurface nanocavities when using STM or STS to address the $\mathrm{Cu}(001)$ surface conductance away from the area right above a nano-object. We have observed multiple long-range narrow interference beams in the $\langle 100\rangle$ directions superimposed on the atomic structure of the substrate, by which an apparent $c(2 \times 2)$ superstructure within the beams is revealed. The slight difference between the inplane lattice constant and oscillation period related to the planar component of the $\langle 101\rangle$ wave vector, leads to a moire pattern that is additionally modified with a periodic phase shift of the apparent surface arrangements. By taking into account the atomic surface periodicity in our previ- ously developed model dealing with injection, propagation, reflection, and interference of electrons, as well as the anisotropy of electronic properties in $\mathrm{Cu}$ [9], an excellent agreement between the experimental and simulated STM images is obtained. Our analysis gives a clear and consistent explanation of the origin of long-range interference beams and the apparent $c(2 \times 2)$ superstructure, and is further strengthened by the observation of similar patterns when using Ne-filled cavities instead of the exclusive use of Ar so far [7-9].

To implant noble gas and form subsurface nanocavities, the $\mathrm{Cu}(001)$ sample was bombarded by $\mathrm{Ar}$ or $\mathrm{Ne}$ with an energy of $5 \mathrm{keV}$ and current density of about $30-80 \mu \mathrm{A} / \mathrm{cm}^{2}$ during $30 \mathrm{~min}$. After the implantation, the sample was annealed at $1000 \mathrm{~K}$ for $5 \mathrm{~min}$. The STM study was done at $77 \mathrm{~K}$ in an ultrahigh vacuum (UHV) "Omicron" STM. The x-ray photoelectron spectroscopy (XPS) analysis made after implantation without annealing reveals the $2 p_{1 / 2}-2 p_{3 / 2}$ double peak of argon (Fig. 1). The

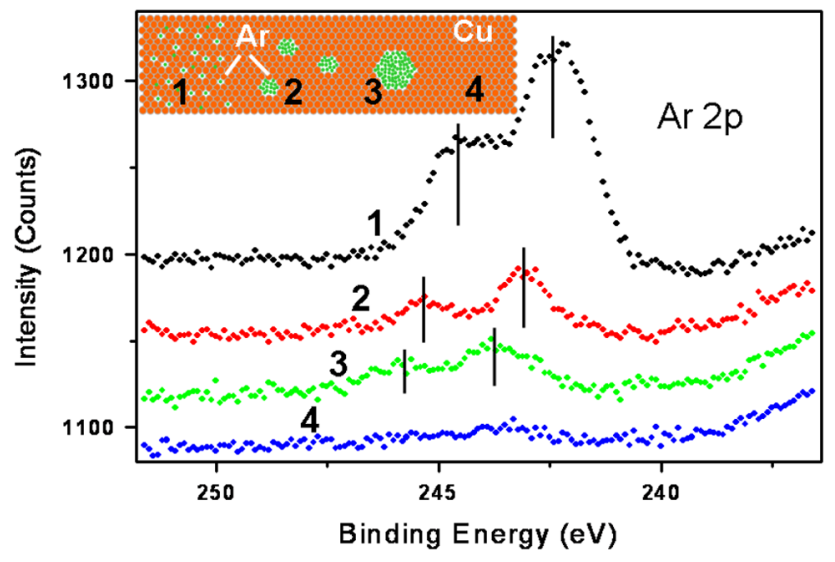

FIG. 1 (color online). XPS spectra of the $\mathrm{Cu}$ sample after implantation of Ar without annealing (1) and annealing at (2) $1000 \mathrm{~K}$, (3) $1050 \mathrm{~K}$, and at (4) $1075 \mathrm{~K}$. The positions of Ar $2 p_{1 / 2}$ and $2 p_{3 / 2}$ maxima of binding energy are marked by the vertical bars. For better visibility the curves 2 and 3 are shifted down by 30 and 60 counts, respectively. The corresponding structure is shown in the inset. 
binding energy corresponds to the values reported elsewhere [11], and it is shifted with respect to the binding energy of free argon, indicating that Ar is implanted in $\mathrm{Cu}$. The shift of the $2 p_{1 / 2}-2 p_{3 / 2}$ peaks back to higher binding energy together with a reduction of their amplitude is observed after annealing at 1000 and $1050 \mathrm{~K}$ for $5 \mathrm{~min}$, showing the formation and growth of Ar-filled nanocavities [12] as well as the loss of argon. After annealing at $1075 \mathrm{~K}$ for $20 \mathrm{~min}$ the argon peaks vanish. Although not specifically tested in great detail, similar processes should take place when implanting $\mathrm{Ne}$ [13]. This shows that thermal treatments allow us to control size and density of the subsurface nanocavities formed by different gases.

Before presenting the main result we would first like to ensure that similar electronic features at the surface are induced by implantation of $\mathrm{Ar}$ or $\mathrm{Ne}$ and annealing at $1050 \mathrm{~K}$. The STS maps reveal a very pronounced variation of the surface conductance above the nanocavities depending on the applied bias voltage $V_{b}$ (Fig. 2). The characteristic size of the spots corresponding to the perturbed conductance is only a few nanometers. Remarkably, the spots in the STS images are strongly anisotropic (Fig. 2) and differential conductance in the center of the spots reveals an oscillation when sweeping the energy (not shown). This points out that the formation of standing electron waves and localized QWs between surface and cavity interface, is a robust and reproducible phenomenon not only restricted to Ar as previously reported [9], but also present for other noble gases such as Ne.

Now the presence of embedded nanocavities and QW formation at the surface is demonstrated, we can focus on the long-range interferencelike beams. These are clearly visible in the STM images at high resolution (Figs. 3 and 4) obtained by mapping of uncompensated tunnel current. This regime is almost the constant height mode of STM except that the feedback loop was closed with a low gain in order to provide stabilization of the mean value of tunnel resistance $R_{t}$. Several specific features of the beams can be distinguished. (i) Typically, four beams spread over a dis-

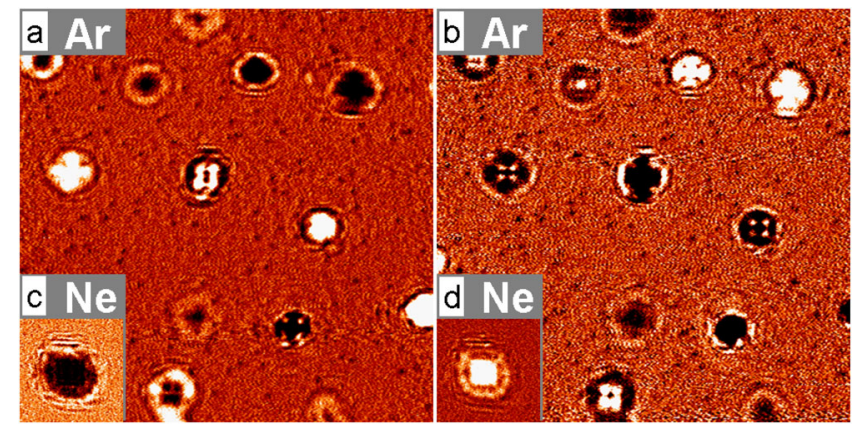

FIG. 2 (color online). Two couples of differential conductance maps of the same $\mathrm{Cu}$ surfaces after implantation of $\mathrm{Ar}$ (a),(b), $60 \times 60 \mathrm{~nm}^{2}$, or $\mathrm{Ne}(\mathrm{c}),(\mathrm{d}), 15 \times 15 \mathrm{~nm}^{2}$, and annealing at $1050 \mathrm{~K}$. The bias voltages $V_{b}$ of (a) $400 \mathrm{mV}$, (b) $600 \mathrm{mV}$, (c) $500 \mathrm{mV}$, and (d) $800 \mathrm{mV}$ were applied at the STS scanning with tunnel current $5 \mathrm{nA}$ stabilized by the closed feedback loop. tance of more than $10 \mathrm{~nm}$ in the $\langle 100\rangle$ directions while they are only about $1.5 \mathrm{~nm}$ wide [Fig. 3(a)]. (ii) The radial beams always start from squarelike concentric rings and never observed at the center. (iii) The radial beams originating from different neighboring nanocavities can overlap without any cross-talk or distortions [Fig. 3(b)]. (iv) A $c(2 \times 2)$ superstructure pattern is observed within the beams, which is, however, not homogeneous, and can have an extra modulation. For some long beams, two or three maxima of contrast on the length scale of $L \approx 3 \mathrm{~nm}$ are clearly visible although other values of $L$ have been observed in different experiments. Within these parts of the beam a shift of rows of the superstructure is observed as shown in Fig. 3(c) and schematically drawn in Fig. 3(d). Later on, we will come back to this surprising behavior. (vi) Usually, four beams are present in STM images. However, very often we observe only one beam [Fig. 4(a)], two opposite [Fig. 4(b)] or two adjacent [Fig. 4(c)] beams, and sometimes three beams. Even if we observe all four beams [Figs. 3(a) and 3(b)], their length and contrast can be unequal. Remarkably, the number of observed beams is generally the same for several nanocavities within one scan of the surface. However, when the tip state accidently changes in time, we observed the appearance/disappearance of extra beams while keeping the atomic resolution of the sur-
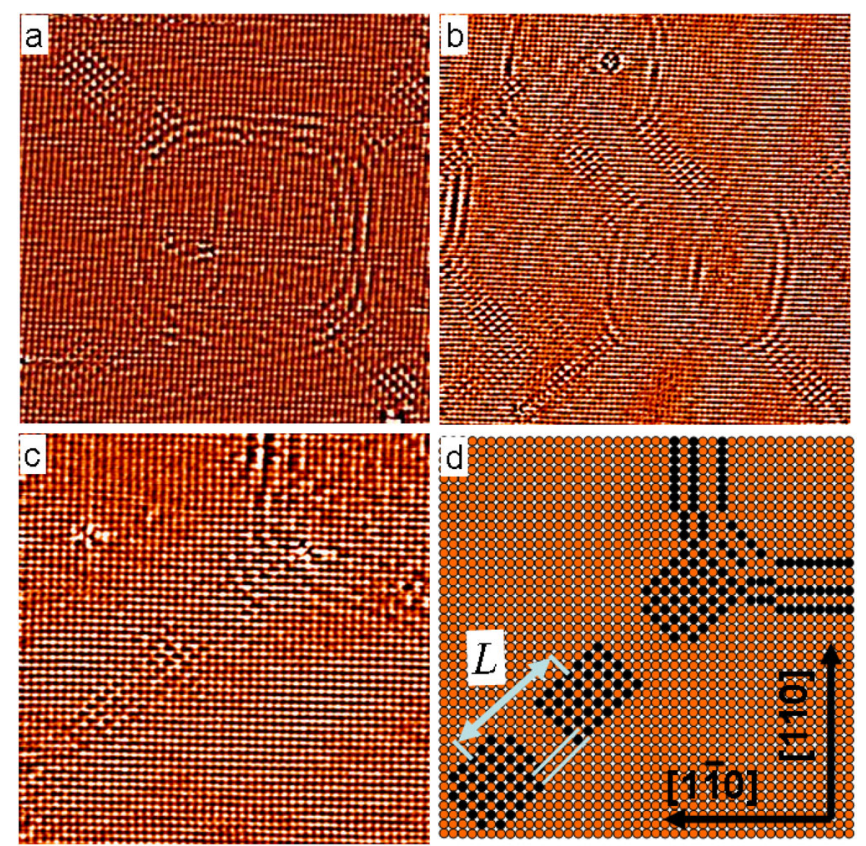

FIG. 3 (color online). (a),(b) and (c) STM images of $\mathrm{Cu}$ surface above the nanocavities with atomic resolution: (a) typical interference pattern above a single Ar-filled nanocavity, $15 \times 15 \mathrm{~nm}^{2}, V_{b}=46 \mathrm{mV}, R_{t}=2 \mathrm{M} \Omega$; (b) several Arfilled nanocavities induce overlapping beams of interference fringes, $18 \times 18 \mathrm{~nm}^{2}, V_{b}=7 \mathrm{mV}, R_{t}=0.05 \mathrm{M} \Omega$; (c) a $c(2 \times$ 2) superstructure within the interference beam near a Ne-filled nanocavity, $12 \times 12 \mathrm{~nm}^{2}, V_{b}=7 \mathrm{mV}, R_{t}=0.1 \mathrm{M} \Omega$; (d) schematic drawing similar to (c) (scale not corresponding) illustrating the shift of the rows within the superstructure. 

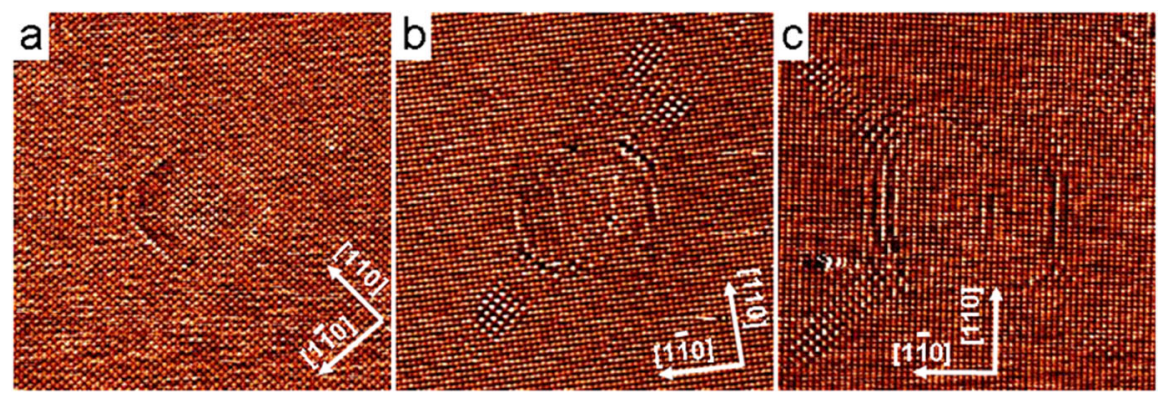

FIG. 4 (color online). Examples of nonequivalent beams of interference: (a) one beam, (b) two aligned beams, (c) two adjacent beams in the left corners. In (b) the extra beam on top of the main structure belongs to a neighboring nanocavity located out of the scanned field. In (c) very weak beams are still visible in the right corners. The field of view is $15 \times 15 \mathrm{~nm}^{2}$. Scanning parameters (a) $V_{b}=-10 \mathrm{mV}, R_{t}=0.1 \mathrm{M} \Omega$; (b) $V_{b}=9 \mathrm{mV}, R_{t}=0.4 \mathrm{M} \Omega$; (c) $V_{b}=10 \mathrm{mV}, R_{t}=0.4 \mathrm{M} \Omega$.

face. All these facts prove that the observed $c(2 \times 2)$ superstructure within the beams is not intrinsically inherent to the atomic arrangement, but an electronic effect, where the tip state is crucial. In fact, the injection in the bulk by a STM tip can strongly relate to the angular distribution of electron $k$ vectors at the tip apex. Although only the component perpendicular to the surface $k_{\perp}$ can be taken into account by a simplest approach for the tunneling process in $\mathrm{STM}, k_{\|}$, which is conserved for elastic tunneling, should determine the $k$ vector of electrons after injection [14]. If $k_{\|}$at the tip end is nonuniform, for example, due to its particular shape and atomic structure, the injection in the bulk should not be characterized with axial symmetry.

If the injection is axial-symmetric, the specific shape of the observed pattern is obviously determined by the inhomogeneous angular distribution of electrons coming back to the surface after reflection from the nanocavity. There are two reasons for this: the bulk anisotropy of the metal and the shape of the subsurface reflector. Our model based on the approach developed earlier [9] takes these two factors into account. In order to describe the features obtained in the present experiments, we modified the model by including the periodical position-dependent tunneling probability corresponding to the atomic structure of surface.

Our model uses the anisotropic band structure of copper $E(\mathbf{k})$ [15]. Moreover, an electron wave can additionally favor only a few specific directions when traveling over a long distance, a so-called focusing effect already studied for other systems $[10,16-18]$, intimately relates to specific features of the band structure. In our experiment, the beams of interference fringes appear always along the $\langle 100\rangle$ directions indicating the concentration of coherent electron waves due to this effect. The shape of the subsurface reflector can also determine particular angles of backscattering and contribute to the formation of the long-range beams especially if it contains flat planes. Several experimental reports $[7,8,19]$ prove the presence of flat facets forming nanocavities in single-crystalline solids. In our model, the interface with the nanocavity is built by three types of differently oriented facets $\{001\},\{110\}$ and $\{111\}$ similarly to a Wulff construction [20].
Results of our calculation and comparison with the experimental data give a typical depth of the nanocavity of 3-15 nm, while the size of the upper facet is estimated to be a few nanometers. The simulation of the conductance map is presented in Fig. 5(a). The simulation shows long radial beams in the $\langle 100\rangle$ directions [Fig. 5(a)] very similar to those observed in the experiment [Fig. 3]. The simulation [Fig. 5(a)] also shows the rounded rectangularlike feature around the center. Additionally, it shows the structure just above the nanocavity which is ill resolved in the experimental pattern with high resolution (Figs. 3 and 4) because of the feedback operation, but appears on the experimental images with low resolution in the STS regime [Figs. 2(a) and 2(b)]. We address readers for these details to our previous publication [9].
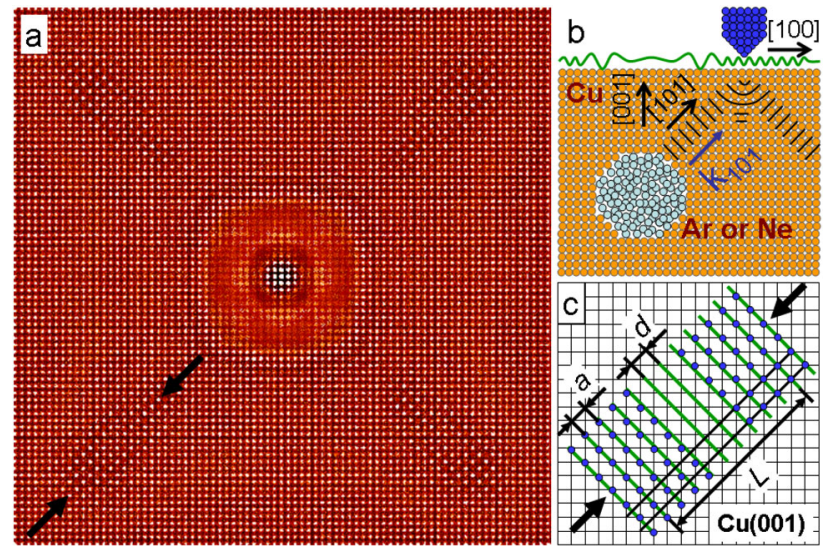

FIG. 5 (color online). (a) Simulated conductance map of $\mathrm{Cu}$ $(001)$ above a nanocavity showing the $c(2 \times 2)$ structure within the beams induced by the nanocavity buried $5.5 \mathrm{~nm}$ below the surface, and with the size of the $\{001\}$ facets of $2.2 \times 2.2 \mathrm{~nm}^{2}$, and the $\{110\}$ facets of $3.3 \times 0.7 \mathrm{~nm}^{2}$; (b) schema of the formation of the interference pattern at the $\mathrm{Cu}(001)$ surface (green line) due to the wave concentrated in the $\langle 101\rangle$ directions; (c) origin of the $c(2 \times 2)$ superstructure and the shift of rows. The grid corresponds to the crystalline lattice of $\mathrm{Cu}$ while the apparent $c(2 \times 2)$ superstructure is shown by spots. The arrows in (a),(c) and guiding lines are to indicate the shifted rows of the superstructure. 
The origin of beams in the $\langle 100\rangle$ directions is the concentration of electron waves along the $\langle 101\rangle$ directions due to the focusing effect in copper, which is shown schematically in Fig. 5(b). The same directions correspond to the $\{101\}$ facets of the nanocavity effectively reflecting the electrons. The length of the beams can depend on several factors. The fundamental limit is the electron mean free path which can reach hundreds of nanometers at low temperature. But there are other factors that are specifically related to the configuration of the system, such as size of the $\{101\}$ facets reflecting electrons, energy spread of the injected electrons, and the signal-to-noise ratio in the STM system. Additionally, a particular tip state can reduce injection of electrons in a direction favorable for focusing leading to a decrease or even disappearance of the interference pattern. Our model does not deal with all these factors and only the size of $\{101\}$ facets determines the length of the beams in the simulated pattern.

The $c(2 \times 2)$ superstructure within the beams appears as a superposition of the atomic arrangement and the interference fringes at $\mathrm{Cu}(001)$ surface schematically shown in Fig. 5(c). The formation of the $c(2 \times 2)$ superstructure is due to the accidental coincidence of the $\mathrm{Cu}$ unit cell size $a$ with the periodicity of interference fringes $d$ at the surface which is determined by the planar component of $k$ vector of electrons propagating in the $\langle 101\rangle$ directions [Fig. 5(b)]: $d=\pi \sqrt{2} / k_{101}$. This gives the opportunity to make a rough estimation of $k_{101}$ from our experiment: $k_{101} \approx$ $1.24 \times 10^{10} \mathrm{~m}^{-1}$, which is close to the tabulated value $k_{F}=1.36 \times 10^{10} \mathrm{~m}^{-1}$ within an isotropic approximation [21]. Additionally, the slight difference between the lattice parameter $a$ and the period $d$ leads to the formation of a moire pattern with a period $2 L$, where $L$ is determined as $L=a d /(2|a-d|)$. As a result, the modulation of the contrast within the beam, and in the shift of arrangement of rows of superstructure indicated by arrows in Figs. 5(a) and 5(c), is formed each half of period $L$. On the one hand, the value $L=3 \mathrm{~nm}$ estimated in Fig. 3(c) allows us to correct the $k_{101}$ presented above to get more precise value, but on the other hand, we realize that this correction can be done only within a simple approach considering the unperturbed band structure of copper. This perturbation should be due to extra stresses in the vicinity of the nanocavity and leads to a slight variation of both the value of $k$ vector corresponding to the focusing direction, and the focusing direction itself. Although we still can define a planar component of the $k$ vector at the surface from experiment, the precise determination of the complete $k$ vector corresponding to focusing desires additional studies. For other materials, if a similar coincidence of lattice parameter and wave vector of reflected electrons is achieved, a similar superstructure can also be observed although other directions of focusing can be considered.

In summary, we have studied the variation of differential conductance of the $\mathrm{Cu}(001)$ surface above buried nanocavities filled by Ar or Ne. Electron focusing plays a crucial role in formation of the interference beams in the $\langle 100\rangle$ directions. Superposition of the interference fringes with the surface atomic structure results in a $c(2 \times 2)$ superstructure, all in perfect agreement with results of our electron interference calculations.

This work was supported by the Dutch Technology foundation (STW) via NWO VICI-grant as well as by the Dutch foundation for the Fundamental Research on Matter (FOM).

[1] N. Knorr, M. A. Schneider, L. Diekhöner, P. Wahl, and K. Kern, Phys. Rev. Lett. 88, 096804 (2002).

[2] I. B. Altfeder, K. A. Matveev, and D. M. Chen, Phys. Rev. Lett. 78, 2815 (1997).

[3] P. B. Johnson and F. Lawson, Nucl. Instrum. Methods Phys. Res., Sect. B 243, 325 (2006).

[4] G. F. Cerofolini, F. Corni, S. Frabboni, C. Nobili, G. Ottaviani, and R. Tonini, Mater. Sci. Eng., R 27, 1 (2000); P. B. Johnson and D. J. Mazey, Nature (London) 276, 595 (1978); 281, 359 (1979); P. B. Johnson, R. W. Thomson, and D. J. Mazey, Nature (London) 347, 265 (1990).

[5] C. Busse, H. Hansen, U. Linke, and T. Michely, Phys. Rev. Lett. 85, 326 (2000)

[6] C.-Z. Liu, L. Q. Shi, Z. Y. Zhou, X. P. Hao, B. Y. Wang, S. Liu, and L. B. Wang, J. Phys. D 40, 2150 (2007).

[7] M. Schmid, W. Hebenstreit, P. Varga, and S. Crampin, Phys. Rev. Lett. 76, 2298 (1996).

[8] M. Schmid, S. Crampin, and P. Varga, J. Electron Spectrosc. Relat. Phenom. 109, 71 (2000).

[9] O. Kurnosikov, O. A. O. Adam, H. J. M. Swagten, W. J. M. de Jonge, and B. Koopmans, Phys. Rev. B 77, 125429 (2008).

[10] J. Heil et al., Phys. Rep. 323, 387 (2000).

[11] P. H. Citrin and D. R. Hamann, Phys. Rev. B 10, 4948 (1974).

[12] C. Biswas, A. K. Shukla, S. Banik, V. K. Ahire, and S. R. Barman, Nucl. Instrum. Methods Phys. Res., Sect. B 212, 297 (2003).

[13] E. Oliviero, S. Peripolli, L. Amaral, P. F. P. Fichtner, M. F. Beaufort, J. F. Barbot, and S. E. Donnelly, J. Appl. Phys. 100, 043505 (2006).

[14] M. Prietsch, Phys. Rep. 253, 163 (1995).

[15] G. A. Burdick, Phys. Rev. 129, 138 (1963); B. Segall, Phys. Rev. Lett. 7, 154 (1961).

[16] J. Heil, M. Primke, A. Bohm, P. Wyder, B, Wolf, J. Major, and P. Keppler, Phys. Rev. B 54, R2280 (1996); S. Knauth, A. Bohm, and W. Grill, Physica B (Amsterdam) 263-264, 220 (1999); J. Heil, M. Primke, K. U. Wurz, and P. Wyder, Phys. Rev. Lett. 74, 146 (1995).

[17] M. Dahne-Prietsch and T. Kalka, J. Electron Spectrosc. Relat. Phenom. 109, 211 (2000); F. J. Garcia-Vidal, P. L. Andres, and F. Flores, Phys. Rev. Lett. 76, 807 (1996).

[18] N. Quaas, Ph.D. thesis, Georg-August University of Gottingen, 2003.

[19] V. Raineri, M. Saggio, and E. Rimini, J. Mater. Res. 15, 1449 (2000).

[20] C. Herring, Phys. Rev. 82, 87 (1951).

[21] CRC Handbook of Chemistry and Physics (CRC Press, Boca Raton, 2003), 84th ed. 